\title{
A ASCESE RADICAL DA FILOSOFIA SCHOPENHAUERIANA E A PROPOSTA SALVÍFICA DO CRISTIANISMO
}

\author{
Jefferson Silveira Teodoro ${ }^{1}$ \\ Faculdades Integradas Machado Sobrinho (FEMS)
}

\section{RESUMO:}

Este trabalho tem como foco a filosofia de Schopenhauer em comparação com a proposta salvífica do cristianismo. Os grandes filósofos metafísicos que precederam Schopenhauer identificaram o objetivo maior do espírito com a realização de sua plenitude. Esta é indicada, paralelamente, no campo religioso, a partir da aproximação do homem com Deus. A novidade que este texto pretende apontar é que, diferentemente da tradição filosófica e religiosa do Ocidente, Schopenhauer realizou em sua metafísica um caminho para o espírito humano no qual a sua "libertação" não coincide com a plenitude do espírito. Para este filósofo a libertação é atingida a partir de uma ascese radical, na medida em que propõe a mortificação/ aniquilação do ser como um todo. É um caminho que passa pela busca da nulidade da Vontade, visando sua suprema aniquilação.

PALAVRAS-CHAVES: Cristianismo; Schopenhauer; Libertação.

\section{THE RADICAL ASCESIS OF THE SCHOPENHAUER'S PHILOSOPHY AND CHRISTIANITY'S SALVIFIC PROPOSAL}

\begin{abstract}
:
This work shows the comparison between the Schopenhauer's philosophy and Christianity's salvific proposal. The great philosophers think out systems or metaphysical questions in which spirit's main goal coincides with the liberation proposal in the various forms of Christian religion. In their systems, the ideal path traced to the spirit coincides with the fullness of being that appears in the religious sphere. The novelty this paper intends to

\footnotetext{
${ }^{1}$ Mestre em Ciência da Religião pela Universidade Federal de Juiz de Fora (UFJF), Minas Gerais - Brasil. Linha de pesquisa: Filosofia e Religião. Professor nas Faculdades Integradas Machado Sobrinho/JF.

E-mail: vontadeerepresentacoes@yahoo.com.br
} 
portray is that Schopenhauer's metaphysical system traces a path to the human spirit in which its liberation does not coincide with the fullness of spirit. Over against the usual trend in Western thought, for this philosopher liberation coincides with a radical overcoming of being, because it proposes the mortification/annihilation of being not only in the carnal dimension, but as a whole. It is a reverse path that seeks the void of the Will in search of its whole annihilation.

KEYWORDS: Christianity, Schopenhauer, Liberation.

\section{Introdução}

A filosofia de Schopenhauer, embora não se apresente como uma variante teológica, pode ser relacionada com algumas das discussões mais profundas da esfera religiosa. Isto porque o cerne da mesma reside em uma complexa sistematização metafísica que compreende pelo menos duas noções interdependentes e imprescindíveis para as religiões. São elas: A libertação da dor e do sofrimento e a pressuposição de que o ser íntimo de toda a realidade é fundamentado a partir de uma instância transcendente e absoluta.

As várias vertentes históricas do cristianismo admitem, de formas diversas, que a existência ordinária do homem está muito distante de um suposto estado de plenitude e liberdade espiritual. Também em outras matrizes religiosas o homem é indicado como um ser que não é pleno, sendo que esta plenitude, esta libertação, pode e deve ser buscada e alcançada através dos caminhos indicados por elas. A este respeito, John Hick (2005) afirma:

\footnotetext{
Bem, é certamente verdade que as ideias de união com a santa trindade, do Nirvana, da retidão da Torá, e assim por diante, são todas diferentes e por isso, únicas. Até aí não há razão para controvérsia. A questão, entretanto, é se são ou não são diferentes formas da meta genérica mais fundamental, que é a de passar de um estado profundamente insatisfatório a um estado ilimitadamente melhor numa relação correta para com o que é fundamentalmente Real. Penso que são; todas diagnosticam o fracasso da vida humana comum "irredenta" de diferentes maneiras - enquanto pecaminosidade resultante da queda, ou como a cegueira do avidya, ou como um centramento da auto-afirmação do eu, e assim por diante (...) (HICK, 2005, p.144-145)
}

Este apontamento fundamental para a libertação não ocorre fora de uma realidade maior que envolve, além da parte que precisa e deseja a salvação ou a plenitude de seu ser, a parte que estabeleceu esta possibilidade e que figura como alvo a ser perseguido. No judaísmo e no cristianismo - 
limitamo-nos aqui às matrizes religiosas predominantes na cultura ocidental - tal "parte" é concebida como absolutamente plena e livre: Deus. ${ }^{2}$

Dessa forma, admite-se neste texto um sentido histórico e ocidental para "religião" que, como defenderam Lactâncio ${ }^{3}$ e Santo Agostinho, está vinculado ao termo latino religare. Este sentido expressa exatamente a necessidade de reaproximação com Deus: "Vós incitais a que se deleite nos vossos louvores, porque nos criastes para Vós e o nosso coração vive inquieto, enquanto não repousa em Vós." (AGOSTINHO, 2000, p.37).

É através deste "religamento", desta reaproximação da criatura com seu criador, que surge no cristianismo a noção de libertação ou salvação. Nesta linha, o objetivo é aproximar-se, agir segundo o ser maior - através da graça e ou esforço- e, com isso, alcançar a realização do próprio ser, vencer o sofrimento, a morte e o pecado.

Não se trata, portanto, de uma simples disposição individual de libertar-se, mas antes, de um plano maior, de uma possibilidade que ocorre através de uma finalidade bem determinada por um ser superior e absoluto. Estar livre do sofrimento, do pecado, alcançar um estado de existência melhor, feliz e pleno é, no fundo, o fim para o qual aponta o cerne do discurso religioso sob o nome que, neste texto, pela conjuntura mais ampla que envolve, chamaremos de proposta salvífica.

$\mathrm{O}$ intuito de comparar a filosofia de Schopenhauer com a proposta salvífica do cristianismo, parte da constatação de que os grandes filósofos que pensaram sistemas ou questões metafísicas fizeram-no identificando o objetivo maior do espírito humano com aquilo que equivale à libertação dentro de formas da religião cristã. Ou seja, os filósofos ocidentais traçaram caminhos para o espírito em que o ideal coincide invariavelmente com a plenitude do ser, com a realização do espírito que aparece paralelamente no campo religioso.

Pode-se identificar este traço mesmo antes do aparecimento do cristianismo no Ocidente, através dos escritos de Platão ${ }^{4}$, que apontam para a libertação do ser a partir da imortalidade da alma:

\footnotetext{
${ }^{2}$ Embora a filosofia de Kierkegaard com sua "infinita distinção qualitativa entre Deus e o homem", e a influente teologia de Karl Barth tenham estabelecido um abismo entre o criador e a criatura, uma condição onde não é possível pensar em uma atitude onde o homem possa se aproximar de Deus (o finito se aproximar do infinito) pode-se identificar nesta mesma teologia a verdade do caminho oposto, ou seja, se por um lado não cabe à ação humana aproximar-se de Deus, cabe e é unicamente possível a Deus aproximar-se do homem através de seu indecifrável desígnio. De qualquer forma, a salvação ou libertação continua vinculada a uma plenitude do ser que, por assim dizer, é escolhido por Deus, o qual se apresenta exclusivamente pela revelação. Ver mais sobre este ponto em: TEIXEIRA, Faustino. Teologia de Las Religiones: una visión panorâmica. 2005, p.43.

${ }^{3}$ Lucius Caecilius Firmianus Lactantius ou Lactâncio era fiel ao espírito apologético do início do cristianismo. Foi preceptor de Crispo, filho do imperador Constantino.

${ }^{4}$ A citação de Platão aqui, embora numa primeira consideração possa configurar um anacronismo pelo fato de que, evidentemente, o cristianismo ter sido uma construção muito
} 
Aqueles, enfim, cuja vida foi reconhecida como de grande piedade, são libertados, como de cárceres, dessas regiões interiores da terra, e levados para as alturas da morada pura, indo morar na superfície da verdadeira terra! E, entre estes, aqueles que pela filosofia se purificaram de modo suficiente passam a viver absolutamente sem os seus corpos, durante o resto do tempo, e a residir em lugares ainda mais belos que os demais (...). Porque a alma é evidentemente imortal - eis uma opinião que me parece boa e digna de confiança. Belo será ter esta coragem! (...) (PLATÃO, 2000, p.114-115)

Nessa mesma linha, onde a imortalidade da alma aparece como evidência ou possibilidade de uma existência pela aproximação com Deus na transcendência, figura também Santo Agostinho:

Falai assim para que eu ouça. Estão atentos, Senhor, os ouvidos do meu coração. Abri-os e dizei a minha alma "sou tua salvação”. Correrei após estas palavras e alcançar-vos-ei. Não me escondais o rosto. Que eu morra para o contemplar, a fim de não morrer eternamente (...) (AGOSTINHO, 2000. p.178)

$\mathrm{Na}$ modernidade, o panteísmo de Spinoza pressupõe que o conhecimento de Deus e seus atributos, melhor dizendo, o próprio conhecimento de si como modo de Deus em um movimento de autoidentificação com aquilo que é eterno e perfeito, seria o caminho para uma realização plena do ser. Esta não se dá em uma futura transcendência, mas a partir do momento que se compreende que desde sempre tudo é instância dos atributos de Deus e, portanto, perfeição divina:

A mente não concebe nada sob a perspectiva da eternidade senão à medida que concebe a essência de seu corpo sob a perspectiva da eternidade, isto é, senão à medida que é eterna. Por isso, à medida que é eterna, a mente tem o conhecimento de Deus, o qual é, com certeza, necessariamente adequado (porque este é eterno e infinito) (...). Portanto, quanto mais cada um se torna forte no conhecimento intuitivo dos atributos de Deus, tanto mais está consciente de si próprio e de Deus, isto é, tanto mais é perfeito e feliz (...) (SPINOZA, 2008, p. 397)

Na filosofia kantiana, Deus é retirado do âmbito do conhecimento metafísico seguro, através dos parâmetros estabelecidos dentro da Crítica da Razão Pura. No entanto, na Crítica da Razão Prática, Kant postulou que o sumo bem só seria possível se a vontade estivesse em perfeita concordância com a lei moral. E como isso consistiria em "uma perfeição da qual nenhum

posterior à filosofia platônica, justifica-se pela profunda influência que o platonismo teve sobre a estruturação teológica do cristianismo. 
ente racional do mundo sensorial é capaz em nenhum momento de sua existência”, seria, portanto, necessário pensar que a alma é imortal, para que nesta imortalidade o sumo bem pudesse ser possível. (KANT, 2002, p. 198)

Entretanto, este progresso infinito somente é possível sob a pressuposição de uma existência e personalidade do mesmo ente racional perdurável ao infinito (a qual se chama imortalidade da alma). Logo, o sumo bem é praticamente possível somente sob a pressuposição da imortalidade da alma (...) (KANT, 2002, p. 198)

Do mesmo modo, seria necessário pensar Deus como aquele que torna possível esta referida imortalidade, porque "somente de uma vontade moralmente perfeita (santa e benévola), ao mesmo tempo onisciente, podemos esperar alcançar o sumo bem.” (KANT, 2002, p. 208)

Hegel desenvolve um sistema regulado pela prerrogativa principal da realização do espírito através de seu autoconhecimento. Neste sistema, em que a história aparece como movimento do espírito absoluto em função deste autoconhecimento, nota-se que mesmo não havendo apelo a uma transcendência explícita, é estabelecido o foco principal para o caminho que o espírito segue em busca de seu estado mais pleno. Este coincide com o conhecimento de si, que se faz e dá a partir da ação realizada na história:

Que o espírito absoluto se tenha dado à figura da consciência de si em si, e, portanto, também para sua consciência, isso agora aparece assim: a fé do mundo é crer que o espírito "é-aî" como uma consciência de si, quer dizer, como um homem efetivo (...) (HEGEL, 2007, p. 508)

Ainda:

O reino dos espíritos, que desse modo se forma no ser-aí, constitui uma sucessão na qual um espírito sucedeu a outro, e cada um assumiu de seu antecessor o reino do mundo. Sua meta é a revelação da profundeza, e essa é o conceito de absoluto (...). A meta - o saber absoluto, ou o espírito que se sabe como espírito - tem por seu caminho a rememoração dos espíritos como são neles mesmos, e como desempenham a organização de seu reino. Sua conservação, segundo o lado de seu ser-aí livre que se manifesta na forma de contingência, é a história; mas segundo o lado de sua organização conceitual, é a ciência do saber que se manifesta (...) (HEGEL, 2007, p. 544545)

Diante do que foi até aqui brevemente exposto quanto à tradição religiosa e filosófica do Ocidente, a novidade trazida pela filosofia de Schopenhauer é justamente que o autor de $O$ Mundo como Vontade $e$ Representação realizou em seu sistema metafísico um caminho para o 
espírito humano no qual seu estado melhor não coincide com a plenitude, com o engrandecimento do ser. Em Schopenhauer, a libertação coincide com uma ascese radical, na medida em que propõe a mortificação/ aniquilação do ser como um todo. É um caminho que passa pela busca da nulidade da Vontade ${ }^{5}$. Vontade esta não concebida em sentido psicológico, mas como instância metafísica absoluta que torna possível a existência de todas as coisas.

Nesse sentido, surge então um "fato novo" para a nossa tradição filosófica, na medida em que temos em Schopenhauer um filósofo ateu, não materialista, que estabelece em sua filosofia o estado de santidade como o ponto máximo para o espírito humano, e onde este estado é obtido através de uma ascese radical que conduz ao aniquilamento.

O homem é sempre remetido a si mesmo, em cada assunto, bem como no principal. Em vão cria para si deuses, para deles obter, por preces e louvores, aquilo que só a sua própria força de vontade pode produzir. (...) Saniasis, mártires, santos de todas as crenças e nomes, suportaram voluntariamente de bom grado todos os martírios, visto que neles a Vontade de vida se suprimia; depois, até mesmo a lenta destruição do fenômeno da Vontade de vida lhes era bem vinda. (SCHOPENHAUER, 2005, p. 419)

\section{A Vontade schopenhaueriana e o Deus cristão}

As razões que fazem com que a ascese proposta pela filosofia de Schopenhauer esteja voltada para uma negação radical do ser, e não para uma afirmação, relacionam-se, necessariamente, com a diferença de concepção entre a verdade metafísica em última instância nos parâmetros do Deus cristão e o conceito schopenhaueriano de Vontade.

Nos escritos de Schopenhauer (2005), a Vontade aparece como elemento fundamental para a estruturação de todo o seu sistema metafísico, na medida em que a mesma é reconhecida como instância última, de onde parte o impulso infinito gerador de todas as coisas. A Vontade move todo o universo, cria a partir das suas representações diretas e indiretas ${ }^{6}$ todas as coisas, desde os mais abstratos sentimentos humanos até a mais firme das rochas. Tanto a força da gravidade como a sede do animal são identificadas

\footnotetext{
5 A exemplo do que fez Jair Barbosa, em sua tradução de $O$ Mundo Como Vontade $e$ Representação (2005), usaremos neste texto o termo Vontade em detrimento da notação vontade, para diferenciar respectivamente o sentido metafísico do sentido psicológico que o termo apresenta dentro da obra de Schopenhauer.

${ }^{6}$ Entende-se aqui por representações diretas, aquelas primeiras representações as quais compõem as ideias perfeitas, a objetividade imediata da Vontade, livre da causalidade. Quanto às representações indiretas devem-se entender aquelas que estão sujeitas ao princípio de causalidade. Ver mais sobre este ponto em: O Mundo Como Vontade e Representação (Capítulo terceiro).
} 
como manifestações em graus diferentes ${ }^{7}$ desta mesma Vontade que se estende por tudo. Tudo pertence à Vontade, tudo acontece a partir deste fundamento universal absolutamente poderoso e livre ${ }^{8}$. Nossa própria vontade "particular" não passa de uma forma análoga, um reflexo da Vontade em sentido absoluto metafísico.

[...] a Vontade não é apenas livre, mas até mesmo todopoderosa. Dela provém não só seu agir, mas também seu mundo [...] Ela determina a si e justamente por aí determina seu agir e seu mundo: estes dois são ela mesma, pois, exterior à vontade não há nada. (SCHOPENHAUER, 2005, p. 355)

É razoável pensar, dadas estas características da Vontade schopenhaueriana, que a mesma poderia assumir o status de Deus enquanto instância metafísica última. De fato, não parece absurdo, à primeira vista, detectar certa equivalência entre aquilo que os cristãos reconhecem como Deus, sob os atributos de onipotência, onisciência e onipresença, e a Vontade. No entanto, a partir de uma investigação um pouco mais detalhada, é forçoso admitir que esta equivalência se dá exclusivamente no sentido de que tanto o Deus cristão quanto a Vontade são fundamentos metafísicos absolutos. Isso quer dizer que não é possível afirmar, sem incorrer numa série de inconsequências conceituais, que a Vontade é uma forma de Deus.

Mas por que a Vontade não pode ser equiparada ao Deus cristão? E, ainda, o que esta questão tem a ver com a diferença entre a proposta salvífica do cristianismo e uma ascese radical da filosofia schopenhaueriana?

A guisa de estabelecer a diferenciação fundamental entre a Vontade em Schopenhauer e a concepção cristã de Deus, dadas as características básicas teologia ocidental, deve-se reconhecer que esta concepção reconhece Deus como onipresente, onipotente, onisciente e bom. Destas quatro características essenciais, só é possível atribuir ao conceito de Vontade em Schopenhauer as duas primeiras. Sim, a Vontade está em tudo e move tudo, produz e fundamenta todas as coisas simultaneamente. A Vontade também pode tudo, na medida em que é absolutamente livre, sem limites impostos por nenhuma força extrínseca. Declara Schopenhauer:

[...] a fim de tornar claro como a Vontade, em todos os seus fenômenos, está submetida à necessidade, enquanto em si mesma é livre, sim, pode ser chamada todo-poderosa [...]. Essa liberdade e onipotência - cuja exteriorização e cópia é todo o

\footnotetext{
${ }^{7}$ Ver mais sobre este ponto em: O Mundo Como Vontade e Representação. Cap. II, p. 187.

${ }^{8}$ E.V. Hartmann chamou o sistema de Schopenhauer de "pantelismo", concepção onde tudo é Vontade, em oposição ao "panlogismo" de Hegel. Cf. SCHOPENHAUER, Arthur. Sobre o fundamento da moral. 2001, p XLV. Cf. MORA, José Ferrater. Dicionário de Filosofia. 2005. Tomo III, p. 2197-2198.
} 
mundo visível, seu fenômeno, o qual se desenvolve progressivamente conforme as leis trazidas pelas formas do conhecimento. (SCHOPENHAUER, 2005, p. 397)

No entanto, a Vontade não pode ser nunca onisciente, porque uma de suas características principais é a irracionalidade ${ }^{9}$. Este ponto específico aponta diferenças entre a concepção judaico cristã de Deus e a Vontade schopenhaueriana, porque na tradição cristã Deus é teológica e filosoficamente concebido como um ser dotado de sabedoria e conhecimento e racionalidade perfeita.

Nesse sentido, atribuiremos a Deus, mas levando-as ao infinito, todas as perfeições de que tenhamos encontrado algum vestígio na criatura. Diremos, assim, que Deus é perfeito, soberanamente bom, único, inteligente, onisciente, voluntário, livre e todo-poderoso, cada um de seus atributos reduzindo-se, em última análise, a não ser mais que um aspecto da perfeição infinita e perfeitamente una do ato puro de existir que é Deus (...) (GILSON, 2007, p. 662)

Ainda:

O simples espetáculo da ordem e da finalidade que reinam no mundo basta, aliás, para mostrar que não foi uma natureza cega que produziu as coisas por uma espécie de necessidade, mas por uma providência inteligente que as escolheu livremente. (GILSON, 2007, p. 663-664)

Em Schopenhauer, como já indicado, não podemos atribuir à Vontade nenhum tipo de planejamento, ordem, harmonia e finalidade. Ela é cega, toda poderosa e irracional:

No confronto do princípio hegeliano, em que o real é o racional, Schopenhauer sustenta que tudo o que é real é irracional (...). Esta não-racionalidade do ser impõe uma dupla exigência metafísica, que satisfaz sua interpretação como vontade: pesquisar de uma vez que elemento de nossa essência, e em seguida, a do mundo, que dá um conteúdo positivo para essa determinação puramente negativa; e esta é a vontade, enquanto simplesmente quer (...) (SIMMEL, 1995, p.77)

Deriva desta irracionalidade, deste contínuo impulso cego da Vontade, um intrínseco conflito, uma crise da Vontade consigo mesma, uma guerra entre suas múltiplas representações, que faz dela um fundamento

\footnotetext{
${ }^{9}$ Corrobora José Ferrater Mora, em seu Dicionário de Filosofia: "Em certos autores, como em Schopenhauer e Eduard Von Hartmann, o mundo é descrito como manifestação de algo irracional ou, ao menos, não racional. Além disso, esses autores, e especialmente Schopenhauer, destacaram o caráter irracional do "Absoluto"”. p.1563- 1564.
} 
universal "nocivo", gerador de sofrimento. Dessa forma, a bondade inerente ao Deus cristão também não pode ser atribuída à Vontade schopenhaueriana.

[...] conflito interno à Vontade, que se objetiva por meio de todas aquelas Idéias, mostra-se numa guerra interminável de extermínio dos INDIVÍDUOS de cada espécie e na luta constante dos FENÔMENOS das forças da natureza entre si [...] O cenário e o objeto dessa batalha é a matéria, que eles se empenham por arrebatar uns dos outros [...] (SCHOPENHAUER, 2005, p. 228)

É possível atribuir, à Vontade, absoluta potência e extensão, também verificadas na ideia de Deus presente no cristianismo, no entanto, não se pode atribuir a ela a onisciência, e nem mesmo um conhecimento parcial, visto que é irracional. Esta irracionalidade também impede qualquer ordem ou direcionamento ligado à realização do bem. Assim, podemos concluir que não pode haver ideia de libertação em Schopenhauer que coincida com a manutenção do ser, com a sua plenitude ao lado do fundamento metafísico último, como ocorre dentro da proposta salvífica do cristianismo.

Dentro do cristianismo é perfeitamente possível vislumbrar uma perspectiva de libertação ligada à plenitude do ser finito, porque Deus é o ser infinito que tudo pode, que está em tudo, e que na sua perfeita sabedoria é bom, garantindo no plano de sua criação um destino e um sentido para tudo e todos. Nesta perspectiva, elementos de toda a suposta criação divina exibem uma evolução e uma finalidade. Por mais que não se compreendam todas as relações de causalidade que constituem o real, julga-se que a realidade esta circunscrita em um planejamento positivo derivado da sabedoria divina, sendo possível caminhar para um estado pleno.

Nesse sentido, cabe muito adequadamente no plano geral do cristianismo a ideia de purificação, que na verdade está identificada com a superação e eliminação de todos aqueles comportamentos e condições que possam afastar o homem, em seu livre arbítrio, da perfeição e plenitude que se creem presentes na figura de Deus.

Por outro lado, quando da análise acerca de que tipo de libertação poderia ser esperado dentro de um sistema metafísico como o de Schopenhauer, verifica-se que a mesma é completamente incompatível com aquilo que se espera dentro do cristianismo.

É necessário atentar para o fato de que, se no cristianismo existe um grande sentido em pensar a libertação, por meio da aproximação do ser criador perfeito, para Schopenhauer este ser simplesmente não existe.

No entanto, existe uma instância toda poderosa, mas que por não ser boa nem racional deve ser antes aniquilada. Ocorre que evitar e anular esta instância, ou seja, evitar e anular a Vontade equivale a aniquilar a si mesmo, uma vez que a Vontade não é uma espécie de "mal" que prejudica o ser 
estando fora dele. A Vontade, pelo contrário, é o próprio fundamento do ser, de todos os seres:

\begin{abstract}
$\mathrm{O}$ atormentador e o atormentado são unos. $\mathrm{O}$ primeiro erra ao acreditar que não participa do tormento, o segundo ao acreditar que não participa da culpa. Se os olhos dos dois fossem abertos, quem inflige o sofrimento reconheceria que vive em tudo aquilo que no vasto mundo padece tormento [...] o atormentado notaria que toda maldade praticada no mundo, ou que já o foi, também procede daquela Vontade constituinte de sua própria essência [...] ${ }^{10}$ (SCHOPENHAUER, 2005, p. 453)
\end{abstract}

Por este motivo fundamental, a ascese proposta dentro do sistema de Schopenhauer não pode ser positiva, não pode apontar para a realização do ser, mas antes, para a radicalidade de uma aniquilação, para um ponto de escape que ao mesmo tempo é nulidade do ser.

Não basta apenas, como propõe boa parte do cristianismo, confiar o fim do sofrimento da existência, a paz e felicidade completas na imortalidade da alma. ${ }^{11}$ Enquanto houver existência haverá a Vontade como seu fundamento e, por este motivo fundamental, não será possível escapar de seu conflito intrínseco.

Há muito reconhecemos esse esforço, constitutivo do núcleo, do em-si de toda coisa, como aquilo que em nós mesmos se chama VONTADE [...]. Pois, todo esforço nasce da carência, do descontentamento com o próprio estado e é, portanto, sofrimento pelo tempo em que não for satisfeito; nenhuma satisfação, todavia, é duradoura, mas antes sempre é um ponto de partida de um novo esforço, o qual, por sua vez, vemos travado em toda parte de diferentes maneiras, em toda parte lutando, e assim, portanto, sempre como sofrimento: não há nenhum fim último do esforço, portanto não há nenhuma medida e fim do sofrimento. (SCHOPENHAUER, 2005, p. 399)

\title{
O autoconhecimento da Vontade e o caminho para a nulidade do ser
}

\footnotetext{
${ }^{10}$ Cabe aqui ressaltar que esta unidade entre o atormentador e o atormentado através de um fundamento comum: a Vontade, não quer indicar que esta sofra algum tormento, em si mesma. Antes, é a sua natureza intrínseca, como força cega e irracional, que gera o sofrimento nos seus fenômenos. Toda a questão ética levantada por Schopenhauer quanto à identificação da existência como sofrimento se aplica aos fenômenos da Vontade, ao mundo como representação, e não à Vontade em si mesma.

${ }^{11}$ Mesmo na concepção cristã que reforça a ideia da ressurreição dos corpos no fim dos tempos, indicado pela narrativa do apocalipse, fica subentendida a imortalidade da alma que, por consequência de um corpo que ressurge para a vida eterna, também é eterna na unidade indissociável entre corpo e alma.
} 
Até aqui este texto se ocupou, primeiramente, em expor o núcleo salvífico do cristianismo como plenitude do espírito, e a sua correspondência na história das teorias metafísicas dos grandes filósofos ocidentais. Coube também apontar a diferença entre esta proposta e aquilo que neste texto denominamos "ascese radical" da filosofia de Schopenhauer. A proposta desta ascese aponta para um destino oposto daquele que o cristianismo e a filosofia ocidental vislumbraram, em diferentes matizes como ideal, na medida em que o ser é suprimido, e não tornado pleno.

A filosofia de Schopenhauer até aqui se mostrou diferente da proposta salvífica do cristianismo em termos de finalidade, cabe agora perguntar qual é o processo através do qual esta referida libertação pelo aniquilamento do ser é possível.

Primeiramente é preciso deixar claro que os indivíduos que são grandes exemplos morais das religiões históricas não são interpretados pela filosofia de Schopenhauer como equivocados quanto ao caminho para a superação da existência de si e do mundo, uma vez que todos eles carregam como traços característicos comportamentos e ensinamentos que estão de acordo com a mortificação dos desejos, com a libertação das paixões, um desprendimento de si movido pela compaixão que, no fundo, para o filósofo, expressa a negação da Vontade.

O apontamento que aqui é necessário fazer é que, em Schopenhauer, esta negação dos desejos não se refere a uma suposta maior ligação com algo superior, um outro mundo, como queria Platão, ou um encontro com o Pai, como se interpretou ter sido o ensinamento de Jesus, que é "símbolo ou personificação da negação da Vontade de vida" e dos santos cristãos. (SCHOPENHAUER, 2005, p. 399)

A negação é radical porque nega absolutamente o ser, não deixando espaço para a perspectiva de uma existência espiritual na transcendência, no além.

Se, portanto, a conduta moral que Schopenhauer "prescreve" não é diferente daquela evidenciada na história da santidade cristã, qual seria, então, o aspecto diferenciador no caminho para este suposto aniquilamento absoluto?

$\mathrm{Na}$ teologia e na história efetiva do cristianismo, nota-se que o caminho para a salvação pode ser realizado por duas vertentes principais: a da graça ${ }^{12}$, mediante a revelação ${ }^{13}$, e a ligada a uma perspectiva mais

\footnotetext{
12 "Dom gratuito; favor feito a um inferior por pura benevolência, remissão de uma pena. Em particular, na linguagem teológica, favor ou socorro de Deus, livremente dados a determinadas criaturas sem que estas tenham qualquer direito a eles." Retirado de: LALANDE, André. Vocabulário técnico e crítico da Filosofia. 1999, p. 450.

${ }^{13}$ Termo de origem latina (revelare) que significa "tirar o véu". Manifestação que Deus faz de si mesmo aos homens por meio de escritores inspirados, profetas e evangelistas. A revelação manifesta-se pela palavra e é codificada em livros sagrados. Às vezes também se manifesta por ações e acontecimentos significativos (...). Retirado de: NAVARRO, Juan Bosch. Para Compreender o Ecumenismo. 1995, p. 227.
} 
determinista/fatalista ${ }^{14}$, relativa a uma suposta predestinação ${ }^{15}$, e a do esforço da liberdade individual, da busca, do exercício espiritual que envolve a reta conduta como caminho para o reino de Deus.

A filosofia de Schopenhauer e a suposta libertação que pode ser identificada dentro do corpo metafísico da mesma tendem a se aproximar da perspectiva determinista:

Ademais, é uma doutrina cristã original dos evangelhos, defendida por Agostinho, em acordo com os mestres da igreja, contra as rasteirices dos pelagianos e cuja purificação de erros e restabelecimento foi o objetivo principal dos esforços de Lutero, como este o declara expressamente em seu livro $D e$ Servo Arbitrio, a de que a vontade não é livre, mas está originariamente propensa ao que é mal. Por isso suas obras são sempre pecaminosas e imperfeitas e jamais podem satisfazer à justiça. Por fim estas obras nunca podem nos salvar: só a fé o pode. Esta, entretanto, não nasce da resolução ou pretenso livre arbítrio e sim pelo efeito da graça, sem participação nossa, como algo que chega de fora para nós (...). Nós, entretanto, reconhecemos na doutrina acima mencionada a verdade que coincide inteiramente com o resultado das nossas investigações (...) (SCHOPENHAUER, 2005, p. 512)

No entanto, não podemos falar expressamente e sem reservas de determinismo, porque o mesmo, na sua versão teológica, pressupõe uma consciência, um planejamento supremo que estabelece o destino do ser - o que não é o caso, dada a já mencionada irracionalidade da Vontade - Ou, em sua versão mais naturalista, se refere à ordem das forças da natureza que, por estarem todas interligadas, produzem uma imutável regularidade na causalidade, da qual não se pode esperar um efeito diferente daquele conduzido por forças e condições físicas específicas (Por exemplo, a certeza da queda de uma pedra ao ser abandonada na superfície terrestre). Este último tipo de determinismo também não deve ser identificado com o tipo de determinismo que pode ser verificado em Schopenhauer.

\footnotetext{
${ }^{14}$ Neste ponto do texto os termos determinismo e fatalismo estão sendo utilizados com certa equivalência. No entanto, é importante atentar para o fato de que ambos os termos possuem significações polêmicas, que nem sempre se identificam. Queremos apontar com estes termos uma determinada impotência da liberdade individual em traçar seu próprio destino que, em nível teológico se refere a buscar ou não, tendo a possibilidade de, atingir sua libertação/ salvação. Sobre este ponto, cf. mais detalhadamente: MORA. José Ferrater. Dicionário de Filosofia. 2004, p. 690-693, 999-1000.

${ }^{15}$ No conselho reformado de 1647, conhecido como "confissão de Westminster, podemos ter um exemplo claro da manifestação da teoria da predestinação dentro da teologia cristã: "Capítulo III (da eterna finalidade de Deus). N ${ }^{\circ}$. "Por decreto de Deus, para manifestação de sua glória, alguns homens e anjos são predestinados à vida eterna e outros são predestinados à morte eterna". Retirado de: WEBER, Max. A Ética Protestante e o Espírito do Capitalismo. 1996, p. 69.
} 
A variante de determinismo que cabe à ascese schopenhaueriana é metafísico e baseia-se na pressuposição de que não é o indivíduo que, se reconhecendo como fenômeno de uma Vontade absoluta, busca a supressão deste "eu" fenomênico, reflexo da representação de algo que é em si mesmo ${ }^{16}$, a Vontade. O que ocorre segundo o filósofo é que a própria Vontade, ao atingir o conhecimento de si mesma, ao reconhecer o seu conflito intrínseco, encontra a possibilidade de sua autossupressão:

[...] é possível uma supressão e autonegação da Vontade em seu fenômeno mais perfeito, quando ela refere um tal conhecimento a si mesma. Assim, a liberdade, do contrário jamais se mostrando no fenômeno, pois pertence exclusivamente à coisa em si, pode neste caso entrar em cena no próprio fenômeno, ao suprimir a essência subjacente ao seu fundamento, embora ele mesmo perdure no tempo; surge daí uma contradição do fenômeno consigo mesmo, expondo deste modo o estado de santidade e auto-abnegação [...] (SCHOPENHAUER, 2005, p. 512)

Surge aqui uma explícita contradição: Se é certo que a Vontade é tomada como irracional em si mesma, também é certo que o estado de libertação alcançado pelo santo caracteriza-se justamente pelo autoconhecimento da Vontade - autoconhecimento este que serve como quietivo, anulador da mesma.

Cabe então ressaltar um aspecto muito importante, que torna possível a superação deste paradoxo. Quando Schopenhauer fala do autoconhecimento da Vontade, ele não se refere à Vontade como coisa em si, mas do fenômeno da vontade que só é possível no homem. Ou seja, só no ser humano a Vontade alcança uma objetivação, uma representação que é capaz de um autoconhecimento, o qual conduz à supressão do ser identificada em Schopenhauer como libertação.

Uma das consequências mais importantes desta concepção, em que a instância metafísica última se autoconhece enquanto unidade fenomênica, é que ela identifica-se com um dos elementos mais inusitados dentro da filosofia de Schopenhauer: A graça. O filósofo afirma que o ato de libertação da Vontade é um acontecimento ligado ao que, no cristianismo, se entendeu por graça.

\footnotetext{
16 A filosofia de Kant, da qual Schopenhauer é herdeiro direto, e se julga legítimo responsável por um "acabamento", deixa um problema em aberto que irá movimentar todo o idealismo alemão, a saber, a do problema da coisa em si. Schopenhauer identifica a incognoscível coisa em si kantiana com a Vontade. Dessa forma, todo o mundo existe apenas como representação desta coisa em si, e não como ela mesma. Ver mais detalhadamente sobre a questão da coisa em si em: BONACINNI, Juan Adolfo. Kant e o problema da coisa em si no Idealismo Alemão. 2003.
} 


\begin{abstract}
Nesse sentido, portanto, o antigo filosofema sobre a liberdade da vontade, sempre contestado, mas também sempre defendido, não é sem fundamento, também não é sem sentido e referência o dogma da igreja sobre o efeito da graça e do renascimento. Agora, porém, vemos inesperadamente ambos coincidirem em um, e podemos doravante também compreender em que sentido o admirável Malebranche podia afirmar: "La liberte es um mystère", e tinha razão. Pois exatamente aquilo que os místicos cristãos denominam EFEITO DA GRAÇA e RENASCIMENTO é para nós a única e imediata exteriorização da LIBERDADE DA VONTADE. (SCHOPENHAUER, 2005, p.510)
\end{abstract}

Ou seja, a negação da Vontade ocorre de maneira aleatória, não sendo fruto de nenhum merecimento. Dentro do determinismo religioso a salvação pela graça é admitida, partindo-se do pressuposto de que existe um Deus sábio que escolhe por desígnios misteriosos. No caso da filosofia de Schopenhauer, a questão se torna ainda mais aguda, no sentido de que não se pode estabelecer parâmetro algum para que a Vontade se negue em um indivíduo específico, dada a sua natureza cega e irracional. Sendo assim, podemos dizer que a "graça" em Schopenhauer é diferente daquela entendida no Cristianismo, porque no mesmo ela é concebida como um ato de intencionalidade divina. É através desta graça "caótica", que não parte de nenhuma consciência ou sabedoria, e unicamente dela, que se pode alcançar a libertação da Vontade.

Por fim, cabe ressaltar que toda a fundamentação moral da filosofia de Schopenhauer vincula-se à compaixão, este elemento tão caro a todas as grandes religiões e geralmente identificado com a capacidade de sentir a dor universal da existência. A compaixão equivaleria para o filósofo ao reconhecimento de que o fundamento do que existe em todas as coisas é o mesmo, e que este fundamento, a Vontade, é autodilacerante.

\footnotetext{
Através, portanto, do fato de que quero imediatamente seu bem e de que não quero seu mal, tão diretamente como se fosse o meu. Isto, porém, pressupõe necessariamente que eu sofra com o seu mal-estar, sinta seu mal como se fora o meu e, por isso, queira seu bem como se fora o meu próprio. Isto exige, porém que eu me identifique com ele, quer dizer, que aquela diferença total entre mim e o outro, sobre a qual repousa justamente o meu egoísmo, seja suprimida pelo menos num certo grau [...] Certamente este processo é digno de espanto e até misterioso. É na verdade, o grande mistério da ética. (SCHOPENHAUER, 2001, p. 135-136)
}

É possível então, após estes desenvolvimentos, vislumbrar o quanto o ateísmo e o pessimismo do autor de $\mathrm{O}$ Mundo Como Vontade $e$ Representação promovem, surpreendentemente, o nascimento de uma 
perspectiva filosófica capaz de assimilar e dar um sentido novo a alguns elementos fundamentais do cristianismo, sobretudo no que se refere à questão da libertação, da graça e do sentido da existência em um mundo que por vezes nos parece o pior dos mundos possíveis ${ }^{17}$.

Efetivamente, a libertação como aniquilação do ser, associada a uma conduta moral baseada na compaixão e regulada pelo que a perspectiva ocidental define como ateísmo, já estava presente no Budismo ${ }^{18}$. No entanto, é preciso diferenciar o pensamento de Schopenhauer de suas aproximações e influências orientais, na medida em que o filósofo é um expoente mais representativo das ideias que nasceram e movimentaram o pensamento ocidental, sobretudo, no que se refere a Platão e Kant ${ }^{19}$.

Nesta mesma perspectiva, que defende a derivação das idéias de Schopenhauer da matriz do pensamento ocidental, este autor pode ser interpretado, como sugeriu Nietzsche, como consequência da crise da visão de mundo cristã, crise esta que se convencionou chamar niilismo.

Em que medida o niilismo schopenhaueriano ainda é sempre a consequiência do mesmo ideal que foi criado pelo teísmo cristão [...] Desaprenderam a reconhecer naquela fixação de ideal também a realidade pessoal [Personen-Realität]: tornaram-se ateístas. Mas renunciaram propriamente ao ideal? - Os últimos metafísicos, no mundo, ainda sempre procuram nele a real "realidade", a "coisa em si", em relação à qual tudo o mais é apenas aparente. Seu dogma é o de que o mundo dos fenômenos não é "verdadeiro" justamente pelo fato, por demais evidente, de que ele não é a expressão daquele ideal - e, no fundo, nem mesmo remonta àquele mundo metafísico como causa. O incondicionado, enquanto é aquela perfeição mais alta, não pode conferir o fundamento para todo o condicionado. Schopenhauer, que desejava que isso fosse de outra maneira, precisou pensar aquele fundamento metafísico como contraposição ao ideal, como "Vontade cega": de tal maneira ela podia ser "o que aparece, o que se revela no mundo dos fenômenos" [...] (NIETZSCHE, 2008, p. 37-38)

\footnotetext{
${ }^{17}$ Aqui se faz uma alusão reversa ao que Leibniz afirmou que este mundo é o melhor dos mundos possíveis, justamente porque se temos a possibilidade do mal é porque temos a certeza da liberdade. Em Schopenhauer o mal é a certeza e a liberdade, no sentido da autonomia da consciência individual, uma ilusão.

${ }^{18}$ Cf. mais sobre este ponto em: ZIMMER, Heinrich. As Filosofias da Índia. 1986.p.326380.

${ }^{19}$ O diálogo de Schopenhauer com estes dois grandes filósofos é, respectivamente, a base indiscutível do conteúdo do terceiro e primeiro livros do Mundo Como Vontade e Representação. O segundo e quarto livros referem-se à postulação da parte mais original de sua obra, a metafísica da Vontade. A obra de Schopenhauer pode ser lida como uma síntese entre elementos diversos absorvidos de Platão e Kant, bem como, em menor escala, sob a influência explicita dos escritos orientais com os quais ele teve contato. Ver mais sobre este ponto em: SAFRANSKI, Rudiger. Schopenhauer y los años selvajes de la filosofia. 1991.
} 


\section{Conclusão}

Pelo que foi aqui brevemente exposto, a ascese proposta dentro do sistema de Schopenhauer não pode ser positiva, nem apontar para uma plenitude do ser, mas antes, revela a radicalidade de uma aniquilação total.

Dessa forma, se considerarmos que os maiores expoentes morais do cristianismo assumiram uma abnegação explícita diante de seus desejos, do egoísmo e da maldade em função de uma ascese espiritual que conduzisse à realização do espírito, deveremos também considerar que a filosofia schopenhaueriana indica um nível de abnegação ainda mais profundo, porque se refere a uma aniquilação absoluta do ser, e não a uma passagem à transcendência, ou mesmo a uma união com Deus.

Esta referida aniquilação da Vontade só pode ocorrer naquela sua objetivação capaz de um autoconhecimento - o homem -, o qual conduz à supressão do ser volitivo identificada como libertação.

\section{Referências bibliográficas}

AGOSTINHO. Confissões. São Paulo: Nova Cultural, 2000.

BONACINNI, Juan Adolfo. Kant e o problema da coisa em si no Idealismo Alemão: sua atualidade e relevância para a compreensão do problema da Filosofia. Rio de Janeiro: Relume Dumaná; Natal: UFRN, 2003.

GILSON, Étienne. A Filosofia na Idade Média. São Paulo: Martins Fontes, 2007.

GOUVÊA, Ricardo Quadros. Paixão Pelo Paradoxo: uma introdução à Kierkegaard. São Paulo: Fonte Editorial, 2006.

HEGEL, Georg Wilhelm Friedrich. Fenomenologia do Espírito. Petrópolis: Vozes; Bragança Paulista: Editora Universitária São Francisco, 2007.

HICK, John. Teologia Cristã e Pluralismo Religioso: o arco Iris das religiões. Trad: Luis Henrique Dreher. São Paulo: Attar Editorial, 2005.

KANT, Immanuel. Crítica da Razão Prática. São Paulo: Martins Fontes, 2002.

KANT, Immanuel. Crítica da Razão Pura. Lisboa: Fundação Calouste Gulbenkian, 1997.

LALANDE, André. Vocabulário Técnico e Crítico da Filosofia. São Paulo: Martins Fontes, 1999.

NAVARRO, Juan Bosch. Para Compreender o Ecumenismo. São Paulo: Loyola, 1995.

MORA, José Ferrater. Dicionário de Filosofia. 2 ed. São Paulo: Loyola, 2003; 2004.1v; $2 \mathrm{v} ; 3 \mathrm{v} ; 4 \mathrm{v}$.

NIETZSCHE, Friedrich. A Vontade de Poder. Rio de Janeiro: Contraponto, 2008

PLATÃO. A República. São Paulo. Nova Cultural, 2000. 
PLATÃO. Fédon. São Paulo. Nova Cultural, 2000.

SAFRANSKI, Rudiger. Schopenhauer y los años selvajes de la filosofia. Madrid: Alianza Editorial, 1991.

SCHOPENHAUER, Arthur. O Mundo Como Vontade e Representação. São Paulo: UNESP, 2005.

SCHOPENHAUER, Arthur. Sobre o fundamento da moral. 2 ed. São Paulo: Martins Fontes, 2001.

SIMMEL, Georg. Schopenhauer e Nietzche. Firenze: Ponte Alle Grazie, 1995.

SPINOZA, Benedictus de. Ética. 2ed. Belo Horizonte: Autêntica, 2008.

TEIXEIRA, Faustino. Teologia de las Religiones: una visión panorâmica. Quito: Abya Yala, 2005.

ZIMMER, Heinrich. As Filosofias da Índia. Palas Athena, São Paulo, 1986. 